\title{
EFEKTIVITAS PROGRAM PEMULIHAN MATA PENCAHARIAN (PAP) DI DESA BATUSARI KECAMATAN DAWUAN KABUPATEN SUBANG 2017
}

\author{
OLEH: \\ ERICK ABRIAND ${ }^{1}$, M. FEDRYANSYAH ${ }^{2}$, GIGIN G. KAMIL BASAR ${ }^{3}$ \\ 1. Mahasiswa Program Studi Sarjana (S-1) Kesejahteraan Sosial Fakultas Ilmu Sosial dan Ilmu Politik Universitas Padjadjaran \\ 2. Pusat Studi Kewirausahaan Sosial, CSR dan Pengembangan Masyarakat Fakultas Ilmu Sosial dan Ilmu Politik Universitas Padjadjaran \\ 3. Departemen Kesejahteraan Sosial Fakultas Ilmu Sosial dan Ilmu Politik Universitas Padjadjaran
}

Email :

( erickabriandi@gmail.com; fedry cons@yahoo.com; giginkb@unpad.ac.id )

\begin{abstract}
ABSTRAK
Tujuan dalam penelitian ini adalah untuk mengetahui efektivitas program pemulihan mata pencaharian di desa Batusari Kabupaten Subang. Metode yang digunakan dalam penelitian ini adalah metode kualitatif deskriptif dengan menggunakan pendekatan sustainable livelihood. Sedangkan dalam pengumpulan data, menggunakan teknik kepustakaan dengan menggunakan beberapa buku dan jurnal sebagai sumber dan juga teknik observasi dan wawancara langsung. Dampak dari pembangunan tol di kabupaten Subang sangat terasa oleh masyarakat yang lahannya harus dijual kepada perusahaan kontraktor pembangun jalan tol. Dampak dari adanya pembangunan tersebut yaitu sebagian masyarakat yang tanahnya merupakan bagian dari project pembangunan jalan tol harus kehilangan mata pencaharian. Untuk itu perusahan kontraktor melakukan tanggung jawab sosial melalui program pemulihan mata pencaharian Person Affected by Project (PAP). Program ini dijalankan oleh IBU Foundation yang bekerja sama dengan mitra langsung yang tersedia untuk project koperasi/UMKM, Gapoktan, PKK tujannya agar ketika program ini sudah diterminasi oleh IBU Foundation, Program ini akan tetap berjalan. Setelah program ini berjalan masyarakat mulai merasakan perbaikan dalam perekonomian terutama di desa Batusari Kabupaten Subang melalui program pemulihan mata pencaharian Person Affected by Project (PAP).
\end{abstract}

Kata Kunci : efektivitas, sustainable livelihood, mata pencaharian

\section{ABSTRACT}

The purpose of this research is to know the effectiveness of livelihood recovery program in Batusari village, Subang Regency. The method used in this research is descriptive qualitative method using sustainable livelihood approach. While in collecting data, using literature techniques by using several books and journals as a source and also techniques of observation and direct interviews. The impact of the development of toll roads in Subang district is felt by the people whose land must be sold to toll road builder construction companies. The impact of the development is part of the community whose land is part of the toll road development project must lose their livelihood. Therefore, the contractor company performs social responsibility through Person Affected by Project (PAP) livelihood restoration program. This program is run by IBU Foundation in collaboration with the direct partners available for the project cooperatives / UMKM, Gapoktan, PKK the purpose is when this program has been terminated by IBU Foundation This program will still run. After the program runs the community began to feel the improvement in the economy especially in the village Batusari Subang District through livelihood programs Person Affected by Project (PAP).

Key words : effectiveness, sustainable livelihood, livelihood 


\section{PENDAHULUAN}

Kemiskinan merupakan masalah yang dirasakan hampir di seluruh negara modern ataupun negara berkembang. Indonesia merupakan salah satu negara yang merasakan masalah kemiskinan. Secara etimologis "kemiskinan" berasal dari kata "miskin" yang artinya tidak berharta benda dan serba kekurangan. Departemen Sosial dan Biro Pusat Statistik, mendefinisikan sebagai ketidakmampuan individu dalam memenuhi kebutuhan dasar minimal untuk hidup layak (BPS dan Depsos,2002). Dalam konteks politik, John Friedman mendefinisikan kemiskinan sebagai suatu ketidaksamaan kesempatan dalam mengakumulasikan basis kekuatan sosial. Frank Ellis (dalam suharto,2005) menyatakan bahwa kemiskinan memiliki berbagai dimensi yang menyangkut aspek ekonomi, politik dan sosialpsikologis. Masih banyak kota atau kabupaten di Indonesia yang tergolong miskin seperti contohnya kabupaten Subang.

Berdasarkan informasi dari badan pusat statistik kabupaten subang pada tahun 2013 yang merilis hasil dari data tahun 2013 dan 2012 menunjukan angka kemiskinan di Subang cukup tinggi, ada sebanyak 162390 penduduk miskin tahun 2013 dari yang sebelumnya 161556 ditahun 2012, jumlah ini menunjukan adanya kenaikan tingkat kemiskinan di kabupaten subang dari tahun 2012 ke tahun 2013 bertambah sebanyak 834 kepala keluarga. Banyak faktor yang membuat angka kemiskinan di kabupaten Subang menjadi cukup tinggi.

Salah satu faktor kemiskinan ini juga terjadi setelah sebagian penduduk di beberapa desa di beberapa kecamatan di Subang kehilangan mata pencaharian yang disebabkan karena lahan yang mereka punya sebagian dijual kepada salah perusahan tol yang bernama PT LMS, yang akan melakukan pembangunan jalan tol disebagian lahan penduduk yang mereka jual kepada perusahaan tersebut.

\section{PEMBAHASAN}

Sebagai bentuk tanggung jawab PT LMS terhadap orang-orang yang terkena dampak dari proyek (Person Affected by Project) pembangunan jalan tol di kabupaten Subang. kemudian PT LMS memilih konsultan CSR yaitu IRM untuk membantu PT LMS mencari data PAP (person affected by project). Program tanggung jawab sosial ini juga merupakan syarat yang diberikan oleh Indonesia Infrastructure Finance kepada PT LMS.

Dari data yang telah didapatkan oleh IRM, ada sejumlah 416 PAP yang akan menjadi target tanggung jawab sosial PT LMS. Kemudian PT LMS memilih IBU Foundation untuk menjalankan memulihkan mata pencaharian orang-orang yang terkena dampak pembangunan jalan tol oleh PT LMS. Program pemulihan mata pencaharian ini merupakan program lanjutan setelah sebelumnya dilakukan di tahun 2014. IBU Foundation telah bekerja sama dengan PT LMS dengan mediasi IRM dari sejak bulan Maret 2014. Kerjasama ini dilakukan untuk memulihkan mata pencaharian PAP (Person Affected by Project) di kabupaten Subang yang terdampak proyek pembangunan jalan tol.

Sebelum menjalankan program pemulihan mata pencaharian IBU Foundation menentukan boundary partner (mitra langsung) yang akan 
diubah perilakunya. Mitra langsung ini diidentifikasi melalui proses Participative Community Meeting. Mereka akan dilibatkan secara intensif, baik itu dalam membentuk kelompok usaha/koperasi maupun dalam melakukan pendampingan kepada PAP (person affected by Project). IBU Foundation memilih bekerja sama dengan mitra langsung yang ada di masing-masing desa agar, ketika program pemulihan mata pencaharian PAP yang dilaksankan IBU Foundation telah selesai, mitra langsung dapat meneruskan program ini secara berkelanjutan untuk menunjang perekonomian dan penghidupan yang berkelanjutan tanpa bergantung dengan IBU Foundation, Berikut adalah outcome dari masingmasing mitra langsung yang dipengaruhi oleh project ini:

Koperasi/UMKM berfungsi menjadi akses pasar dan penyedia modal bagi usaha yang dijalankan PAP dan Non PAP yang kuat, dapat dipertanggungjawabkan, dan berkelanjutan. Mitra langsung ini mengembangkan dan memperkuat kapasitas pengurus dan anggota, baik dalam hal manajemen usaha, manajemen organisasi, dan perluasan jejaring pasar dan modal. Koperasi/UMKM bekerja sama dengan PKK dan Gapoktan, pemerintah khususnya pemerintah desa dan dinas koperasi, tokoh masyarakat, dan institusi lainnya dalam mencapai tujuan mereka. Koperasi/UMKM membuat sistem pemantauan dan evaluasi partisipatif untuk terus meningkatkan kinerja mereka.

Kemudian selain ada koperasi/UMKM ada juga gapoktan, gapoktan bekerja sama dengan PKK dalam memantau, mengembangkan, dan memperluas budidaya tanaman sayur di tataran keluarga; bekerja sama dengan Koperasi ketika aset pertanian-peternakan yang dimiliki PAP berpotensi menjadi kelompok usaha agribisnis. Selain dengan Koperasi/UMKM dan PKK, Gapoktan menjalin koordinasi intensif dengan pemerintah desa, tokoh masyarakat, dinas pertanian, dinas peternakan, dan BPDAS untuk mendapatkan dukungan material dan pengetahuan/keterampilan.

Gapoktan mengintegrasikan bidang pertanian dan peternakan dampingannya dengan rencana strategis pembangunan desa. Gapoktan meningkatkan kapasitas, kualitas manajemen organisasi, dan sistem pemantauan dan evaluasi partisipatif, agar dapat melakukan semua fungsi di atas.

Tidak hanya ada peroject Koperasi/UMKM dan gapoktan, ada juga project PKK yang telah ada di setiap desa memobilisasi, mendampingi, dan memantau pengembangan budidaya tanaman sayur bekerja sama dengan Gapoktan, sehingga penanaman sayuran dilakukan oleh PAP dan warga non PAP secara berkelanjutan. PKK mendampingi dan mengorganisir kelompok usaha olahan pangan dan anyaman bambu yang berbasis produksi rumahan; sehingga berperan dalam pembentukan Koperasi/UMKM yang terkait dengan jenis usaha tersebut. PKK berkontribusi dalam membangun dan mengembangkan sistem usaha simpan pinjam yang telah ada atau membangun unit usaha simpan pinjam di bawah naungannya untuk desa yang belum memiliki koperasi. PKK mendampingi warga masyarakat baik PAP dan Non PAP dalam hal tata kelola keuangan keluarga sehingga mereka mampu memenuhi kebutuhan hidupnya, mengalokasikan dana asuransi dan investasi pendidikan dan kesehatan. PKK mengintegrasikan 
program ini dengan program utama mereka sehingga mendapatkan dukungan dari pemerintah desa secara berkelanjutan. PKK meningkatkan kapasitas, kualitas manajemen organisasi, dan sistem pemantauan dan evaluasi partisipatif, agar dapat melakukan semua fungsi di atas.

Dalam menjalankan ketiga project Koperasi/UMKM, gapoktan dan PKK IBU Foundation terlebih dahulu melaksanakan perencanaan dan membuat indikator - indikator keberhasilan yang harus dicapai selama ketiga project dalam program pemulihan mata pencaharian Person Affected by Project (PAP) agar dalam tahap pelaksanaan nya berjalan sesuai indikator keberhasilan yang telah ditentukan sebelumnya. Kemudian, setelah tahap pelaksanaan tentu saja IBU Foundation harus melakukan monitoring dan evaluasi langsung terkait pelaksanaan program pemulihan mata pencaharian Person Affected by Project (PAP). Penelitian ini merupakan penelitian yang cukup penting. Di dalam penelitian ini peneliti harus mengetahui bagaiamana efektivias dari program pemulihan mata pencaharian Person Affected by Project (PAP) ini dari mulai perencanaan, pelaksanaan, kemudian monitoring dan evalusi, hal ini harus diketahui peneliti karena IBU Foundatin telah menentukan indikator keberhasilan dalam tahap perencanaan hingga ke tahap pelaksanaan dan yang terakhir yaitu tahap monitoring dan evaluasi.

Salah satu desa di kabupaten Subang yang terkena dampak pembangunan jalan tol dan salah satu yang dijadikan target program pemulihan mata pencaharian PAP yaitu desa Batusari yang berada di kecamatan Dawuan. Penduduk di desa ini merupakan salah satu yang terbanyak terkena dampak pembangunan tol yaitu ada 53 PAP dari total keseluruhan 416 PAP (person affected by project). Jumlah ini didapatkan dari data yang dimiliki IBU Foundation.

Dalam menjalankan Program pemulihan mata pencaharian PAP ini IBU Foundation tentunya telah menentukan indikator keberhasilan yang akan dicapai agar setiap tahap dari mulai perencanaan, pelaksanaan, monitoring dan evaluasi dapat berjalan secara efektif dan efektivitas. bagaimanakah efektivitas program yang riil dari program pemulihan mata pencaharian PAP oleh IBU Foundation yang berkerja sama dengan mitra langsung yang di laksanakan di desa Batusari?

Penelitian ini menggunakan landasan teori yaitu pendekatan sustainable livelihood. Peneliti merasa bahwa sustainable livelihood merupakan landasan teori yang tepat untuk sebuah program pemberdayaan dari program pemulihan mata pencaharian Person Affected by Project (PAP). Karena tujuan dari program ini adalah mitra langsung dapat terus menjalankan program ini walaupun IBU Foundation melakukan terminasi.

Pengertian Penghidupan Berkelanjutan (sustainable livelihoods), Pendekatan sustainable livelihoods menempatkan masyarakat sebagai pusat pembangunan. Fokus pada masyarakat ini sama pentingnya baik pada tingkat yang lebih tinggi (ketika membahas pencapaian tujuan-tujuan seperti pengentasan kemiskinan, pembaruan ekonomi atau pembangunan yangberkelanjutan) maupun pada tingkat mikro atau masyarakat (dimana dalam beberapa kasus pendekatan ini sudah banyak digunakan) (Saragih, dkk,2007:7). 


\begin{tabular}{|l|l|l|l|l|}
\hline Jurnal Penelitian \& PKM & Juli 2017 & Vol 4, No: 2 & Hal: $129-389$ & ISSN \\
\hline
\end{tabular}

\section{TINJAUAN PUSTAKA}

Menurut Saragih (2007) Livelihood dapat dimaknai sebagai strategi mencari nafkah, yaitu berbagai upaya yang dilakukan seseorang untuk memanfaatkan berbagai sumberdaya yang dimilikinya untuk mendapatkan penghasilan sehingga mampu mempertahankan kelangsungan hidupnya. Pendekatan Sustainable Livelihoods berusaha mengidentifikasi

hambatan-hambatan paling besar yang dihadapi oleh manusia, dan peluangpeluang yang paling menjanjikan dan terbuka bagi, masyarakat, terlepas darimana asalnya (misalnya disektor mana, pada wilayah mana atau tingkat apa, dari lokal sampai internasional). Pendekatan ini dibangun di atas pengertian atau definisi masyarakat sendiri mengenai hambatan dan peluang tersebut dan, bila memungkinkan, pendekatan ini selanjutnya bisa membantu masyarakat membicarakan/menyadari hambatan dan peluang tersebut (Saragih,dkk, 2007:7).

Sumber Daya Penghidupan Berkelanjutan (sustainable livelihoods capita) Kemampuan untuk mengejar penghidupan dapat ditemui perbedaan tergantung pada kebijakan sosial (kebijakan adat dan kebijakan masyarakat) serta kekuatan masingmasing sumber daya yang dimiliki suatu keluarga atau individu, keadaan sesungguhnya dimasyarakat (kondisi alam dan lingkungan). Pada pendekatan penghidupan berkelanjutan (sustainable livelihoods) memiliki

beberapa sumber daya yang digunakan dalam sebuah penghidupan berkelanjutan, sumber daya- sumber daya ini merupakan sumber untuk mencari tingkat kerentanan sekaligus sebagai alat untuk pencapaian penghidupan yang berkelanjutan.

\section{a. Sumber daya alam (natural capital)}

Sumber daya alam adalah sumber daya yang berasal dari daya alam (tanah, air, udara, sumber daya genetik dll) dan keadaan lingkungan (siklus, hidrologi polusi tenggelam dII) (Scones,1998:7). Sumber daya alam yang ada di sekitar masyarakat dan berguna bagi

kehidupan, seperti: lahan pertanian, hutan, kualitas air tanah, hasil tambang, pantai dan sungai, dan sumber daya lainnya yang disediakan oleh alam. Tanah pertanian yang diusahakan secara intensif dan terus-menerus selama berpuluh-puluh tahun akan mengalami penurunan kesuburan. Masyarakat juga menyadari bahwa penurunan kualitas dan jumlah sumber daya alam dikarenakan eksploitasi alam yang terus-menerus.

b. Sumber daya ekonomi atau keuangan ( financial capital)

Sumber daya keuangan berupa sumber daya dasar (tunai, kredit atau utang, tabungan, dan sumber daya ekonomi lainnya, termasuk peralatan infrastruktur, produksi dasar dan teknologi) yang sangat penting untuk mengejar setiap strategi mata pencaharian (Scones, 1998: 8).

Kepemilikan sumber daya serta akses terhadap lembaga keuangan formal bagi masyarakat miskin, sulit untuk mendapatkan kredit dan pinjaman untuk tujuan apa pun, bila tidak ada kebijakan pemerintah yang mendorong ke arah ini. Akibatnya 


\begin{tabular}{|l|l|l|l|l|}
\hline Jurnal Penelitian \& PKM & Juli 2017 & Vol 4, No: 2 & Hal: $129-389$ & ISSN \\
\hline
\end{tabular}

masyarakat miskin seringkali harus meminjam uang ke rentenir dengan sewa aset yang tinggi.

c. Sumber daya manusia (human capital)

Sumber daya ini berupa aset yang ada pada diri manusia yakni keterampilan, pengetahuan, kemampuan tenaga kerja, kesehatan yang baik dan kemampuan fisik, yang mampu memberikan sumbangan dalam pencapaian penghidupan berkelanjutan (Scones, 1998:8).

Sumber daya manusia mencakup keterampilan, pengetahuan, kemampuan untuk bekerja keras, serta kesehatan jasmani yang semuanya memungkinkan orang menerapkan berbagai macam strategi mata pencaharian untuk mencapai sasaran kehidupannya.

\section{d. Sumber daya sosial (social capital)}

Sumber daya sosial Berupa sumber daya sosial (jaringan, klaim sosial, hubungan sosial, afiliasi, dan asosiasi) dimana dapat menarik orang ketika mengejar strategi penghidupan yang berbeda dan membutuhkan tindakan yang terkoordinasi (Scones, 1998: 8). Tindakan yang terkoordinasi ini seperti peraturan yang ada di masyarakat setempat, kelembagaan sosial, kepercayaan diri, potensi konflik dan lain sebagainya. Rendahnya sumber daya sosial ini berdampak kepada rentannya kaum miskin, karena tidak mempunyai dukungan dari sosial (berupa kelembagaan) sehingga sulit untuk melangkah menuju penghidupan yang cukup.

e. Sumber daya fisik (physical capital)
Sumber daya ini meliputi infrastruktur dasar seperti: jalan raya dan transportasi, pasar/tempat berjualan, bangunan irigasi, perumahan, dan sebagainya. Untuk daerah pertanian, prasarana irigasi menjadi hal yang sangat penting karena mampu meningkatkan hasil pertanian mereka.

Pada Gambar 01 dapat dilihat bahwa sumber daya, yang meliputi berbagai sumber kapital (Sumber daya manusia, sumber daya alam, sumber keuangan, sumber daya sosial, dan sumber daya fisik) yang merupakan satu kesatuan yang tidak terpisahkan. Berbagai aspek tersebut layaknya menjadi kebutuhan yang diperlukan secara bersamaan untuk menunjang sekaligus menjamin keberlangsungan strategi penghidupan masing-masing individu. Ketersediaan akses terhadap sumber kapitalpun berpengaruh terhadap proses pembentukan bahkan perubahan struktur dalam masyarakat. Lebih jauh lagi hal tersebut berpengaruh terhadap pendapatan dan keberlanjutan rumah tangga.

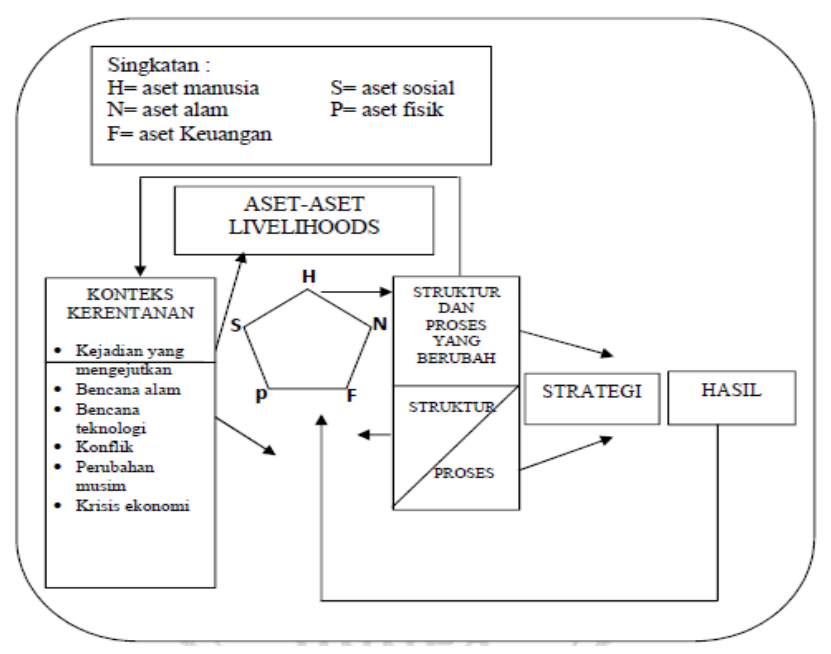


Gambar 01. Kerangka penghidupan berkelanjutan (Di Terjemahkan dari DFID 1999, Sustainable Livelihood Guidance Sheets).

Pendekatan sustainable livelihoods ini dibangun dengan keyakinan bahwa masyarakat membutuhkan sejumlah sumber daya untuk mencapai hasilhasil livelihoods yang positif. Tidak cukup hanya sejenis sumber daya untuk mencapai hasil-hasil penghidupan yang jumlahnya banyak dan berbeda-beda tersebut. Apalagi bagi warga miskin/marginal yang aksesnya pada capital atau sumber daya cenderung sangat terbatas. Sebagai akibatnya mereka harus mencari cara untuk memperoleh dan menggabungkan berbagai sumber daya yang benar-benar mereka miliki dengan cara yang inovatif guna mempertahankan hidup (Saragih, dkk, 2007:25).

Kekuatan seseorang atau masyarakat ditentukan oleh besar/kecilnya, keragaman, dan keseimbangan antar sumber daya. Misalnya orang atau komunitas yang hanya memiliki uang banyak tetapi tidak memiliki sumber daya kekerabatan maka akan hidup didalam komunitas yang tidak aman. Keluarganya dan dirinya mungkin terancam hidupnya, atau jika dia atau keluarganya menghadapi bencana maka tidak ada dari kerabatnya yang akan membantunya.

Pemahaman akan sumber daya sangat berguna untuk menyusun entry points yang sesuai untuk membangun proses pemenuhan kebutuhan dari kelompok sosial yang berbeda, dan juga untuk menggali lebih jauh kemungkinan melakukan pertukaran antara sumber daya yang berbeda. Keseimbangan antar sumber daya sendiri merupakan ke khasan komunitas tertentu yang mengakibatkan betapa pentingnya kepekaan untuk menggambarkan keakuratan penggambaran sumber daya yang dimiliki.

\section{Daftar Pustaka :}

Nelson, Hussein Karim .1998. Sustainable Livelihood and Livelihood Diversification. IDS Working Paper 69.

Raharjo, ST. 2015. Assessment untuk Praktik Pekerjaan Sosial dan Kesejahteraan Sosial. Bandung: Unpad Press 2015. Dasar Pengetahuan Pekerjaan Sosial. Bandung: Unpad Press. 2015. Keterampilan Pekerjaan Sosial: Dasar-dasar. Bandung, Unpad Press.

Sollesbury, W.2003. Sustainable Livelihoods: Case Study The Evolution of DFID Policy.Working Paper 217. London: Overseas Development Institute.

Scoones, I. 1998, Sustainable Rural Livelihood: $A$ Framework for Analysis. IDS Working Paper

http://www.ids.ac.uk/files/dmfile/Wp72. pdf $(16 / 05 / 2017)$

Saragih, dkk.2007. Kerangka Penghidupan Berkelanjutan.

http://www.zef.de/module/register/medi a/2390 SL-Chapter1.pdf (26/05/2017)

Pedoman proposal IBU Foundation Program Pemulihan Mata Pencaharian PAP Tahun 2015 